\title{
Possibilities of determination of soil organic matter content and its quality using near infrared spectroscopy in different ecosystems
}

\author{
Menšík L. ${ }^{1}$, Kunzová E. ${ }^{1}$, Nerušil P. ${ }^{1}$, Pospíšilová L. ${ }^{2}$, Hlisnikovský L. ${ }^{1}$, Kulhavý J. ${ }^{3}$ \\ ${ }^{1}$ Division of Crop Management Systems, Crop Research Institute, Prague, Czech Republic, \\ ladislav.mensik@vurv.cz \\ ${ }^{2}$ Dept. of Agrochemistry, Soil Science, Microbiology and Plant Nutrition, Mendel University in Brno, \\ Czech Republic \\ ${ }^{3}$ Dept. of Forest Ecology, Mendel University in Brno, Czech Republic
}

Keywords: near-infrared spectroscopy techniques, soil organic matter, humic substances, humic acids, arable soil, grassland, forest

doi: 10.36291/HIT.2019.mensik.040

Soil organic matter (SOM) plays an important role in terrestrial ecosystems (agroecosystems, grasslands and forests). SOM is very important in maintaining fertility and in improving physical, biochemical and biological soil properties. Classical analytical (laboratory) methods of determination SOM (carbon /SOC/, humic substances /HS/, humic acids /HA/ etc.), which are accurate and sufficiently reproducible, but at the same time very often demanding on staff working in a specialized laboratory, further on time (relatively long time to determine the result), but also on financial means. The aim of the study is to present new possibilities of determination of SOM content and its quality /HS, HA/ using NIRS.

Identical soil samples from different ecosystems (arable land, grassland, forest) were measured using classical laboratory methods and on a FOSS NIRSystems 6500 instrument dispersive spectrometer (Company NIRSystems, Inc., Silver Spring, USA). Sample scanning was set in reflectance mode for the 400-2500 nm range. WinISI II software (Infrasoft International, Inc., USA), version 1.50, Partial Least Squares (PLS) and modified PLS were used to develop calibration equations and graphical outputs.
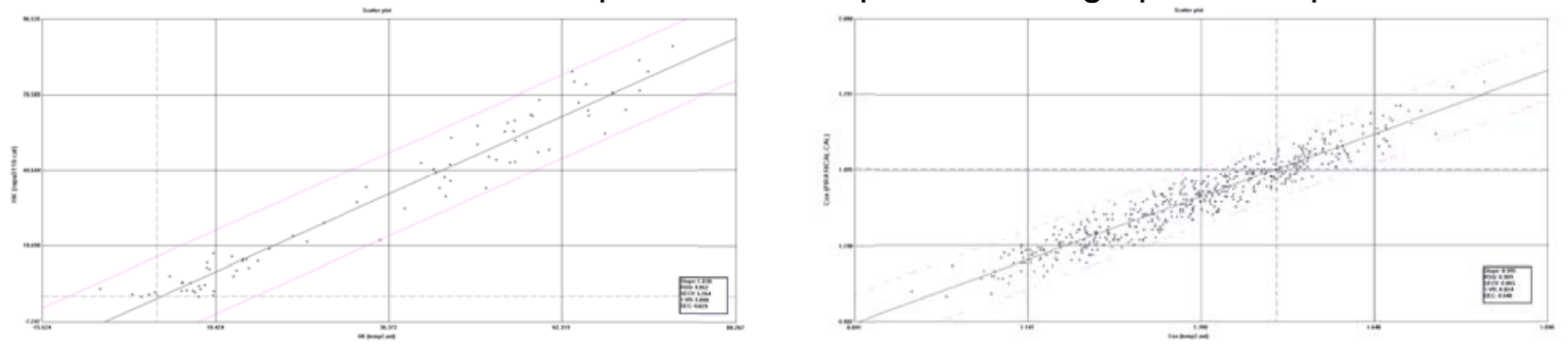

Figure 1. Tightness of the relationship between laboratory analysis and NIRS prediction of SOC in agriculture soil /arable land/ (left) and HA in forest soils (right).

The precision of the determination, expressed as the value of the determination coefficient $\left(R^{2}\right)$ of the calibration set $(n=130-550)$ for the SOM parameters (Corg, HS, $\mathrm{HA})$, is in the range of $0.85-0.99$ (0.80-0.90 applicable) for common agricultural or forestry practice (0.90 or more excellent). Measurement (determination) is sufficiently accurate, safe to work and has no negative impact on the environment.

Acknowledgement. The work was supported by the project MZe RO-0418, NAZV No: QK1810010 and QK1810233.

References

1. Menšík L. et al. // In: Jambor V., Malá S. 18th International Symposium Forage Conservation, Mendel Univerity in Brno, August 13-16, 2019, Brno, Czech Republic, pp. 190-197. ISBN 97880-7509-670-8. 